\title{
An Intercultural Orientation to Languages Education: Expanding Identity Repertoires
}

\author{
Michelle Kohler* \\ Research Centre for Language and Cultures \\ University of South Australia \\ Michelle.Kohler@unisa.edu.au
}

\begin{abstract}
With the rapid and wide reaching movement of people, ideas, products, and practices, we are more interconnected and interdependent than at any other time in history. While there may be some critique of this phenomenon, globalization will remain a pervasive force and education systems around the world are asking how they might best prepare their young people for the challenges of the future. Indonesia is no exception and it too is considering its place and identity in the region and the world, and how education may empower young generations to participate globally, without surrendering their local identity and values.
\end{abstract}

An intercultural orientation in education means understanding communication, knowledge creation and the acts of teaching and learning themselves as linguistically and culturally situated and mediated practices. These practices necessarily involve meaning making and meaning exchange within and across diverse linguistic and cultural systems (Kramsch 2008). It involves recognizing learners' knowledges and their diverse lifeworlds as the starting point for teaching and learning (Liddicoat \& Scarino 2013) and it entails actively building on this diversity to participate in and reflect upon phenomena in the world, and through reflexivity, expand learners' identity development.

In this paper, I will outline why an intercultural orientation is warranted in education and offer contemporary understandings related to how it may be conceptualized. I will then explore how an intercultural orientation may be realized in practice using a range of examples drawn from a long-term program of research with teachers in a range of educational contexts. The paper concludes by asking how an intercultural orientation may be relevant for education in Indonesia and considering some of the implications for how it might be realized.

Keywords-intercultural orientation, language education, identity repertories.

\section{INTRODUCTION}

Let me begin by outlining my line of thinking in this paper. Initially, I will consider the changing nature of education in contemporary times as a result of globalization and emerging paradigms and power shifts. Then I will turn to how education is transforming, and in particular the question of how to prepare future generations for participation in a highly diverse and complex world. I will consider the notion of learning to live together, and the crucial role of languages education in the knowledge, communication and identity project of education. I will outline key understandings that underpin an intercultural orientation, and how this relates to identity development. I will share three examples from our work with educators and conclude with implications of an intercultural orientation, and invite you as educators in the Indonesian context to reflect on what these ideas may mean for you.

While my focus will be on languages education in particular, these ideas have the potential to apply more broadly across the Arts, Humanities and Social Sciences, indeed to any discipline area. This is the because when we learn a language, we are not just acquiring a new code for what we already know, but we are developing new knowledge and new ways to know, as Halliday (1993, p. 94) explains:

When children learn language, they are not simply engaging in one kind of learning among many: rather, they are learning the foundation of learning itself. The distinctive characteristic of human learning is that it is a process of making meaning - a semiotic process; and the proto typical form of human semiotic is language.

Language is the most powerful means we have for expressing our thoughts and feelings and for making sense of new concepts and experiences. But knowledge is not disembodied, and in the process of constructing new knowledge, we are also making sense of each other, teacher and student, student and student, as we seek to understand and interpret how we express ourselves through language. This mutual process of learning to interpret the other is integral to the development of identity - we begin to ask: Who I am as the teacher, who my students are, and who might they want to be? The resources that we have for interpreting the world, and each other, are the language/s and culture/s that we bring to the teaching and learning experience in any area of learning. Hence, let us consider how this plays out in languages education, while pondering how it may apply to other areas of education.

\section{PARTICIPATING IN AND NAVIGATING DIVERSITY}

Two decades into the $21^{\text {st }}$ century we find ourselves in tumultuous times with 
global shifts, in economic and political power, mass movement of peoples, a dramatic transformation of knowledge, of communication practices and of technologies, and an existential threat to our planet and species. While these changes may have been occurring to some extent for a long time, they are now more rapid, more extensive and more intensive, creating new pressures and challenges for societies. Arising from this macro context is the challenge for education of how to prepare our global citizenry for a future that is likely to be more volatile, dynamic, and uncertain. These questions are being explored by educators across the globe, as is evident in statements such as the OECD 2030 goals for education (OECD, 2019).These goals charge education with responsibility for equipping young people with the knowledge, skills, understandings and dispositions to not only cope with these changes but to flourish as human beings and shape the future for the better.

Education is fundamentally a 'peopled' activity, and education for this century will need to attend to a multiplicity of diversities; of learners, knowledges, communication practices and meaning systems, including languages, and technologies. As 'superdiversity' (Blommaert, 2013) is increasingly the norm, assumptions of homogeneous communities and student populations can no longer be made. Education must respond to, and embrace diversity, indeed diversities, as not only a characteristic of students, but as constitutive of the educative experience for all. Being able to deftly navigate diversity with sophisticated communication repertoires is likely to be a decisive feature in whether individuals and communities can learn to live together and continue to grow in their knowledge and understandings.

Education systems and educators around the world are engaging with these ideas through notions such as internationalization, international mindedness, global citizenship, intercultural understandings and values based education. These ideas manifest in various forms including statements of goals and curricula, and increasingly through assessment and notions such as micro credentialing. Let me give some examples.

In Australia, the Australian Curriculum (ACARA, 2011) includes a set of seven capabilities, known as the 'General Capabilities', that must be included in each learning area. One of the capabilities is 'intercultural understanding' framed largely as learning to understand other cultures. Furthermore, at the senior secondary level there are discussions about ways to expand how we credential learning with interest in developing learner profiles that might, for example, include both subject grades or scores and a statement of learners' capabilities such as critical and creative thinking, and intercultural understanding.

Another example, in which I recently participated through a debate style colloquium at the Sorbonne University in Paris, is a rethinking of the goals of modern foreign languages education in a globalizing Europe. Language educators are considering how to respond to new realities resulting from transnational flows of people, languages and cultures (Risager, 2006). There is a growing critique that macro frameworks such as the Common European Framework of Reference are overly generalized and insufficient to cater for highly diverse multilingual communities and that interculturally oriented curricula and pedagogies are needed.

Within the Indonesian context, there is a further example in the Character Education Action Plan (Kementerian Pendidikan Nasional, 2011) that was introduced as part of an emphasis on citizenship and strengthening the national culture and unity in the face of globalization.

A central theme in these examples is how to enable young people to participate effectively in increasingly diverse communities, and communicate within and across borders of various kinds, as part of fostering human rights, respect and social cohesion. An intercultural orientation starts with the premise of diversity, as it assumes that teaching and learning are sociocultural acts of meaning creation and exchange through language, as Gee (2008, p. 100) explains:

A sociocultural approach places a premium on learners' experiences, social participation, use of mediating devices (tools and technologies) and position within various activity systems and communities of practice. The word 'culture' has taken on a wide variety of different meanings in different disciplines. Nonetheless, it is clear that as part and parcel of our early socialisation in life we each learn ways of being in the world, of acting and interacting, thinking and valuing and using language, objects and tools that critically shape our sense of self. A situated/sociocultural perspective amounts to an argument that students learn new academic 'cultures' at school (new ways of acting, interacting, valuing and using language, objects and tools) and, as in the case of acquiring any new culture, the acquisition of these new cultures interacts formidably with learners' initial cultures.

This perspective is one that recognizes the 'person' and all that he or she brings to learning, and the act of learning itself as a kind of enculturation into new ways of knowing and being. This process is particularly heightened in the learning of additional languages, where the distances between languages and cultures are greater than may be readily apparent within a 'single' language and culture. Languages education, within an intercultural orientation, is distinctive in developing learners' capabilities to navigate difference, to enter into new ways of knowing, seeing and being, through participating directly in a new culture through acquiring its language/s. There are many facets to this orientation but I will focus particularly on those related to identity, that is: knowing the learners, conceptual understandings and goals, and pedagogical stance. 


\section{(a) Knowing the learners}

Taking learners' backgrounds into account in their learning is not new in education but it is often associated with learning styles, interests and even traits. These views tend to render what learners bring to the classroom as somewhat static or predetermined and as such offer a limited view of the potential of learners' resources for learning (Gutiérrez \& Rogoff, 2003). Instead, an intercultural orientation foregrounds all that learners bring, bound in a notion of their lifeworlds (Liddicoat \& Scarino, 2013). Of particular importance are their life experiences, discursive practices, and linguistic and cultural frameworks and identities that constitute their dynamic, resources for meaning making. It is both who learners are and what they know, as well as their ways of being and knowing that form the basis for further learning.

Learners' histories and experiences, their knowledges, discourses and languages, represent the primary foundation on which they develop new knowledge, and new ways of knowing and being. The language/s that learners bring from their primary socialization are both an existing linguistic system for communicating, and a basis for conceptualizing, interacting, and expressing identity, in all areas of learning. In Australia, learners typically bring English as their first language to schooling and English is the language of instruction. Increasingly children are coming to school with languages other than English, and learn English at school including through targeted English as an Additional Language programs, sometimes continuing to learn the first language through support programs. Then students are also introduced to a second/foreign language such as Japanese, Italian, or Indonesian. In the Indonesian context, learners will typically come with a local or regional language, some oracy in Bahasa Indonesia, and develop their literacy in Bahasa Indonesia, the language of instruction in schools. In both contexts, these various languages come to represent the learner's linguistic and cultural repertoire or resource for communicating and learning. It is also their identity source, and they navigate, nourish and perform aspects of identity according to needs and desires. The learner's personally held language-and-culture or 'linguaculture' (Risager, 2012) impacts on their knowledge, proficiency, how they learn and demonstrate learning, and who they are as learners. An intercultural orientation is a strength-based view of learners, one that recognises where learners are at, not just in terms of their needs but in terms of the assets and desires that they bring as a basis for learning and development.

\section{(b) Conceptual understandings and goals}

An intercultural orientation in language teaching and learning is underpinned by understandings that have developed as part of a paradigm shift in applied linguistics. For more than forty years, communicative competence has dominated the goals and orientation of language teaching. A communicative competence view assumed a native speaker of the target language as the norm hence the aim for second language learners was to develop proficiency like a native (monolingual) speaker. Studies of bilinguals and multilinguals however have challenged this norm, proposing instead that multilinguals actively use their existing language/s in the process of learning an additional language, developing specific competences or 'multicompetence' (Cook, 1992) that monolingual native speakers do not. Multilinguals also draw on their overall linguistic resource to construct meanings in new configurations in a process of translanguaging (Garcia \& Wei, 2015). In addition, learners are not just exchanging words and ideas in communicating with others; they are exchanging symbolic meanings, histories, values and identities, requiring a 'symbolic competence' (Kramsch, 2006). That is, communication is more than a transaction to exchange words, but it is a relational act of identity exchange. Furthermore, it is recognized that the process of communicating mutlilingually and becoming multilingual is a deeply affective one, involving aspects such as desire, investment and affiliation (Norton, 1995; Prior, 2019).

These theoretical insights have led to efforts to develop a transdisciplinary conceptual framework for second language acquisition (The Douglas Fir Group, 2016) and a reconceptualization of the goals of language learning (Leung \& Scarino, 2016). These reframings also take into consideration the expanded understandings of the concepts of language, culture and learning that have emerged in recent decades and which form the pillars of an intercultural orientation. It is worth briefly considering how each of these is understood in contemporary times.

Firstly, we have seen an expansion from a structural view of language as code or form, to one of language as social semiotic, a dynamic, embodied resource for making meaning. As Shohamy (2007, p. 4) explains:

Language is open, dynamic, energetic, constantly
evolving and personal. It has no fixed boundaries,
but is rather made of hybrids and endless
varieties resulting from language being creative,
expressive, interactive, contact- and dialogue-
based, debated, mediated and negotiated.
... Language is a unique phenomenon as it is
personal and individual and varies drastically
from one user to another.

There has been a similar expansion in relation to understandings of culture. The shift can be characterized as one from culture as facts and information, to the practices or ways that a particular group behaves, to a view of culture as 'webs of significance (Geertz, 1973) or shared discursive practices. These practices are the lenses through which individuals and groups interpret the world around them, and each other. Like language, culture is understood as dynamic, mobile and embodied.

Understandings of learning have also expanded, from a view that it involves accumulating facts, to applying knowledge, to a view that learning involves both. 
Furthermore, learning is an interpretive process, one in which knowledge is seen as embodied, as culturally and linguistically bound and situated. Thus, learning is a process of interpreting knowledge, ways of knowing, and the knowers, those who embody knowledge, including teachers and learners themselves (Scarino, 2014).

Taken together, these understandings foreground the dynamic, interpretive and situated nature of communication and of learning. These concepts come together in an intercultural orientation, not as a method or approach but as an overall mindset, a way of 'seeing and doing' that permeates every aspect of teachers' work. I will focus on intercultural language pedagogy and in particular two aspects that are particularly pertinent for identity: personalization and reflection.

\section{(c) Pedagogical stance}

\section{Personalization}

In learning an additional language, learners are acquiring a new linguistic and cultural system in addition to their existing one. This is not a matter of simply adding or replacing the existing with the new, but it is a process of re-ecologising their linguistic and cultural framework. To do this, learners must build connections that make sense to themselves between the new and the existing language/s and culture/s. They learn to move between the systems, interpreting, adjusting and assimilating new forms, meanings, and ways of meaning, in a continual process of forming their communicative repertoire. Developing new ways of knowing and expressing oneself in the world, leads to expanded ways of being, of identity.

In adopting an intercultural orientation, consideration needs to be given to how learners are positioned in their learning experiences to enable this expansion. That is, learners need to be active participants, developing and using their languages for communication. At the same time, learners are making connections, being attentive to how language works, the new and their own, learning how to move between them. They become analyzers, exploring the system of language, developing a meta-language for talking about language, and considering the connections between language and culture. Furthermore, learners are making judgments about the 'new', reacting and adjusting to it, and evaluating which aspects to take on board or not as part of their identity. In an intercultural perspective, thus, learners have multiple roles as performers, analyzers and persons (Liddicoat \& Scarino, 2013).

In order for learners to take on these roles, they need to be afforded opportunities that are meaningful to them, who they are and who they want to be. Typically, in language teaching, we have devised activities and tasks that have assumed a native speaker role and learners have been required to be someone other than who they are, for example, role play being a becak driver, or for English learners, perhaps ordering in a fast food restaurant in America. While this could be seen as imaginative, typically it is not treated as such as learners pretend to be someone they are not. Within an intercultural orientation learners are encouraged to be themselves, emergent bi/multilinguals who bring their own knowledge, experiences, assumptions, and values to the learning opportunity. They do not 'leave behind' who they are but rather it is brought to the fore as the primary resource for engaging with and experiencing the new. The notion of 'experience' is an important one when education is viewed as a process of socialization and becoming. Learners are continually presented with experiences, deliberate and incidental, and these are transformed by them to become something memorable and retained, or something irrelevant and discarded. Learners need to be presented with experiences that they care about, that draw on who they are, their worlds, and their identities. From the learner's perspective, each new experience builds on previous experiences, both in relation to the language and culture being learned and the learner's existing language and culture. That is, the process is one that is both intercultural and intracultural, and a cyclical one that involves the learners in noticing, comparing, reflecting and interacting (Liddicoat \& Scarino, 2013). These processes are particularly beneficial for learning within an intercultural perspective when accompanied by a pedagogical stance that encourages inquiry, interpretation, discussion and reflection (Scarino, Kohler, \& Benedetti, 2014).

Teachers are the principal shapers of learning experiences and of the kinds of engagement and processes that learners carry out. The discourse of the classroom, and particularly teacher talk and questioning processes are particularly important in creating the learning culture and setting expectations about what is valued learning. Teacher talk may involve encouraging learners to notice a particular aspect, to make connections with their existing knowledge, to explore and investigate aspects, to personalize and offer their interpretations and perspectives, to critique and challenge ideas and representations. This kind of talk is beyond similarities and differences, it is a relational view, one that recognizes the continual process of connecting new and existing knowledge. This may involve noticing similarities and differences of phenomena, but it needs to go deeper than this to understanding the ideas, perspectives, practices and values that underpin these. It means teachers need to ask open-ended questions such as 'What do you make of this? Why do you see it that way?' It means inviting a range of perspectives, 'What do you think of Ari's reaction? Do you agree? Why/why not?' In this way, learners are encouraged to notice language choices, interpretations and reactions, including their own and how others also receive them. In addition, teachers prompt learners to consider the situatedness of participants, and how their linguistic and cultural make-up impacts on interaction and meaning. For example, 'Why do you think Zainah has that view' or 'What do you think should Sara do? What is your view based on?' Learners bring their own perspectives, values and experiences to bear on what is 
presented to them, and in doing so, not only invest in the learning but begin to understand themselves more deeply.

These kinds of interactions take place in relation to stimuli or artefacts, typically textual, as a basis for developing both language for use, and intercultural reflection. Texts are instances of language and culture, and what teachers choose to provide will represent a particular view to learners of what is being learned. An intercultural orientation does not necessarily require any particular kinds of texts, although texts created for use within the culture of the language of study are closest to authentic instances of language and culture in use. It is both the range of texts and what teachers do with them that is most important within an intercultural orientation. Texts of all types, ranging in complexity and origin, with diverse depictions of culture and diverse perspectives are essential for encouraging both interpretation and understanding language and culture, and how they relate, in the expanded sense discussed previously. Importantly, teachers can facilitate exploration of texts by encouraging comparison, juxtaposition, critique and evaluation of the language used and its impact. Texts may come from different historical periods, or different groups, or use multiple languages such as signs or conversations in which people use bahasa campur. This kind of teaching can be demanding, as it is highly responsive and sometimes confronting if we are genuinely open to what learners bring and how they see the world. It means we need to create a culture of learning that encourages openness, curiosity, multiplicity and variability, and at times ambiguity and divergence. This 'pedagogy of personalisation' is in itself rich but for it to be transformative for learning and of learners, it rests on the process of reflection.

\section{Reflection}

An intercultural orientation to learning and language learning in particular recognizes that learners are not only developing a new language for communicating, but they are developing new possibilities for understanding and interacting in the world. In contemporary times, learning to communicate is not enough, and learners also need to understand the process of meaning making itself (Kramsch, 2006). Reflection is crucial to developing learners' awareness, both of how language and culture shape meaning, and of how identity impacts on meaning in interactions within and across languages and cultures. Additionally, reflection enables learners to stand back from their own language and culture, and come to understand how they are situated, and how this shapes who they are as learners and communicators.

Reflection needs to be of the kind that is substantive rather than superficial. That is, questions that probe interpretations and assumptions, that challenge norms and ask learners to consider alternatives are particularly helpful. For example, asking students to question their own assumptions, 'Where does your view come from?' or those that invite seeing another perspective such as 'How would this look from the view of an older person?' Learners consider the phenomena being learned as well as their responses and reactions, reflecting on the nature and impact of these, and on how they relate to their own positioning and linguistic and cultural framework. They reflect on, 'where does my reaction come from?', 'Why did I react like that?' or 'Why do I assume that...?' By doing this kind of reflecting, learners come to see how their identity shapes their interactions and interpretations, and their become aware of what aspects they wish to adopt or not. This is not a whimsical process, but requires a profound consideration of identity, of the nature and extent to which a learner may expand his/her repertoire of being. This identity work is also not a neutral process, as it involves learners' affiliations with the language and culture being learned, and of their wider socio-political contexts.

\section{FINDINGS AND DISCUSSION}

\section{Examples of an intercultural orientation in languages education}

As I mentioned previously, an intercultural orientation is more a matter of mindset than method. It requires a conceptual and pedagogical shift that takes time. In Australia, through the Research Centre for Languages and Cultures in particular, we have been working with this orientation for more than two decades through a sustained program of policy and program development, and practice based research with teachers of various languages at all levels of education. There are numerous project reports and publications that outline the processes and findings of this work but I want to highlight three recent examples that demonstrate an intercultural orientation at different levels of practice. The first is an example of a learning area within a national curriculum; the second is a system wide statement on learning; the third is a student response within a teaching program.

The first example is the Australian Curriculum that sets out the curriculum with some variation at the state level, that all schools are expected to follow. In the Languages learning area, we argued for language specific curricula in order to attend to learners' diverse backgrounds and needs, and to articulate the distinctive nature of content and learning within particular languages. The underpinning orientation was a multilingual and intercultural one, organized around two macro strands, Communicating and Understanding and a set of sub-strands that elaborated aspects such as reflection. 
Table 1: The set of strands and sub-strands of the Australian Curriculum: Languages

\begin{tabular}{|c|c|}
\hline Strand & Sub-strand \\
\hline \multirow{4}{*}{$\begin{array}{l}\text { Communicating: } \\
\text { Using language for communicative purposes in interpreting, } \\
\text { creating and exchanging meaning }\end{array}$} & 1.1 Socialising \\
\hline & 1.2 Informing \\
\hline & 1.3 Creating \\
\hline & 1.4 Translating \\
\hline .. & 1.5 Reflecting \\
\hline \multirow{3}{*}{$\begin{array}{l}\text { Understanding: } \\
\text { Analysing and understanding language and culture as resources } \\
\text { for interpreting and shaping meaning in intercultural exchange }\end{array}$} & 2.1 Systems of language \\
\hline & 2.2 Language variation and change \\
\hline & 2.3 The role of language and culture \\
\hline
\end{tabular}

(Scarino \& ACARA, 2014, p. 11)

The curriculum is currently being implemented and it is clear that it poses a significant challenge for language teachers that will take time as they learn to reorient their practices and overall stance. This example also highlights that a program of teacher professional learning must accompany curriculum initiatives that seek to bring about a fundamental reorientation of teaching practice.

The second example is a position paper prepared for the Minister for Education in South Australia. The paper seeks to bring together three strands of education: Multicultural
Education, Languages, including English as an additional language, and Internationalization of Education, through the theme of 'Learning as Intercultural Engagement'. The central tenet of the paper is that linguistic and cultural diversity is not something belonging to particular groups, typically viewed as ethnically based, but that it is inherent to all learners and represents the foundation for all learning. As such, the premise is that all educators are responsible for actively engaging with linguistic and cultural diversity as the norm, for all learners.

\section{Figure 1: The role of languages, cultures, learning and knowing across the curriculum as a whole}

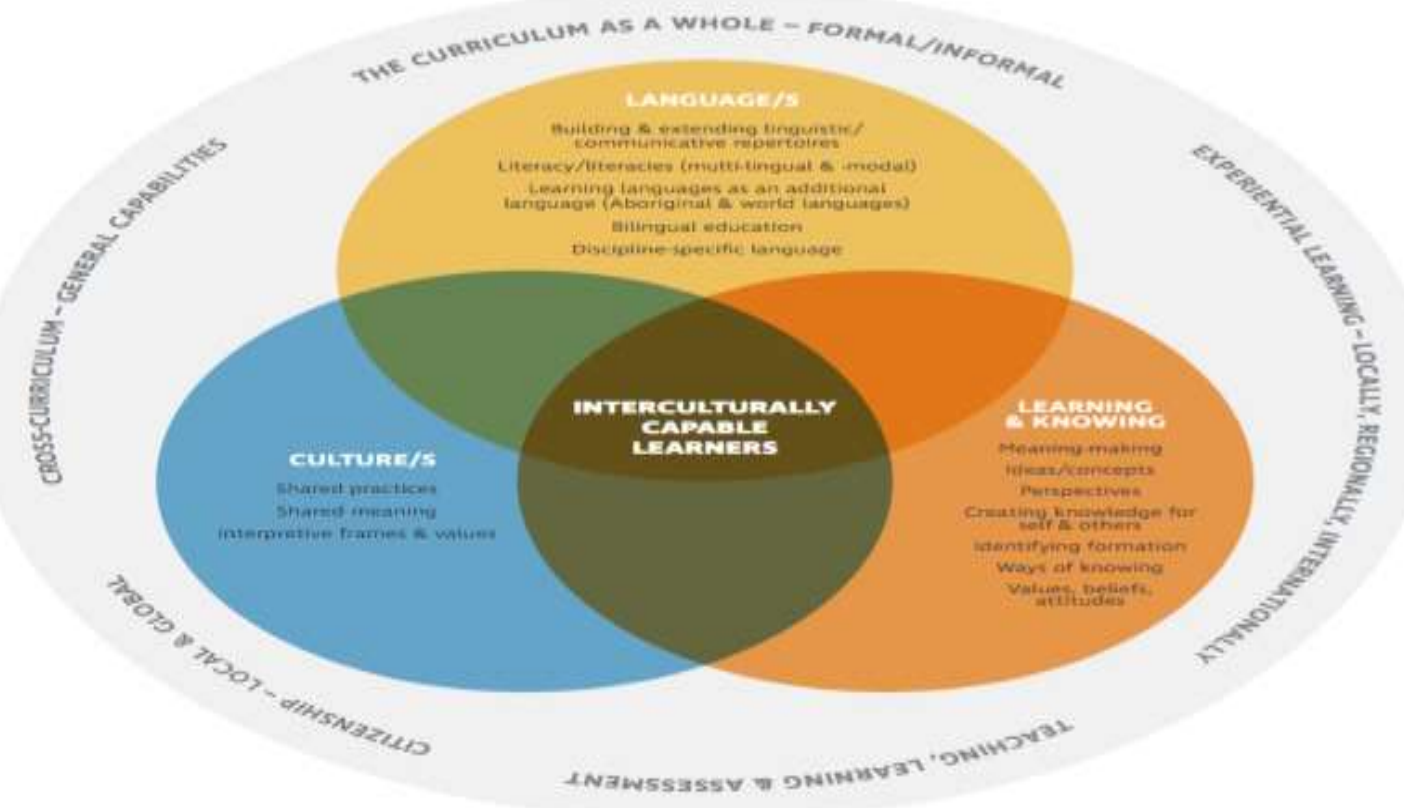

(MELC, 2018, p. 10). 
The paper also outlines a set of principles and actions for various stakeholders across the education systems in South Australia. This example shows that it is possible to bring together strands across education into a coherent narrative around diversity that brings it from a peripheral concern for some students to a mainstream concern for all related to educational achievement, equality and social cohesion.

My third example is the most micro, showing a student response to an assignment in a university course for second language learners of Indonesian. It is an example from my own program that I developed with an intercultural orientation, and this was the final assessment in which students were required to bring together all of their learning to complete a two part assignment. In part 1, learners were required to use Indonesian to develop a bilingual and bicultural resource for an Indonesian person or family coming to Australia, to prepare them to 'fit in'. In part 2, learners were asked to reflect in English, as their first language, on their overall learning in the course and their identity.

Throughout a series of assignments, some text based, others ethnographic and experiential, learners were encouraged to keep a journal of their observations about language and culture, about their responses and reactions in interacting and using language. This is the final reflection of one student, Emma:

Studying Indonesian has been extremely eyeopening for me and has made me analyse Australian culture through a much more critical lens. My language and culture studies of Indonesia, a highly collectivist society with strong identity ties to religion, has really illuminated the individualistic nature of Australian society and made me question what Australian identity, particularly my identity, is based on.

I have come to the conclusion, after studying Islam in Indonesia... that my identity is largely based on my political beliefs and personal values that I have drawn from various sources, like my parents, my schooling or feminist thinkers. Before this year, I would have assumed that my identity was much more open to challenge and discussion than a person whose identity is constructed from religion but I really do not think that is true.

Emma's example shows the working assumptions (collectivist and individualistic) that she brought to her learning of Indonesian, and it shows her awareness of these. It also shows how being presented with another language and culture enabled her to question her own, and to examine her own situatedness and identity. The response indicates how her assumptions were made visible, challenged and changed through her language learning, and how the experience made her more aware of identity and its role in interaction. The response also indicates that this rich identity work may have gone unnoticed by the teacher and learner, if the assessment had not been deliberately designed to elicit reflection.

\section{CONCLUSION}

Whether it be designing a national curriculum for schools, or articulating a vision for an education system, or developing an individual teaching program, adopting an intercultural orientation is a matter of how we 'stand' in relation to linguistic and cultural diversity in education. Given this, it is not possible to outline all of the implications for teachers and their work, as it is perspective that permeates all aspects of teaching, learning and assessing. Of particular importance are the areas of teacher professional learning, with a strong focus on program design, pedagogy and assessment literacy within an intercultural orientation.

Any endeavour must start with the learners, who they are, the kinds of diversities that they bring, their language/s and culture/s, and their affiliations and identities. These are the foundational resources for language learning and indeed all learning, when learning is understood as social and cultural. In addition, learning must be seen as a cognitive, social and interpretive process that comprises experiences that are meaningful for learners within their lifeworlds. Moreover, learners must be invited to reflect, on language, culture and their relationship, on communication, and on themselves in relation to others. It is the expansion of resources for knowing, exchanging meaning and being, made possible through learning new language/s and culture/s, that enable the learner to shift position, inquire into identity, and consider who they are and want to be.

As a final reflection, I want to suggest that this orientation is not neutral, and it is situated in a humanistic view that aspires to the betterment of individuals and society through education. Criticality and self-awareness is part of an intercultural orientation and these features may not be conducive to every context. The notion of identity expansion implies a kind of change that may not be universally appreciated and may even clash with a different ideological framework.

In discussing identity development during prolonged engagement with a second language, Mercer (1990, p. 43) argues that:

Identity only becomes an issue when it is in crisis, when something assumed to be fixed, coherent and stable is displaced by the experience of doubt and uncertainty.

Acquiring a new language is not always a voluntary act or positive experience, as identity may be a matter of choice but it may also be a matter of what is ascribed to us by others (May, 2001). A national or ethnic identity, for example, is one that we may be born into and remains in some way with us, whether we like it or not. It may be that 
introducing another language and culture is seen as disruptive to such identities, if they are seen as uniform or static, as it may dislodge or replace them. The identity development that takes place when learning a new language and culture need not be seen as 'additional' or undermining existing identities (Block, 2014) but rather as expanding them. After all, it is the nature of interculturality to evaluate what is presented and determine how well it 'fits' with one's existing frames and identities, and how it may or may not be made one's own.

Globalization and new technologies have brought an intensity and complexity to the reality of modern life and learning to navigate this will require increasingly sophisticated communication and interpersonal practices.

\section{REFERENCES}

ACARA. (2011). Curriculum Design Paper Version 3.1. Retrieved from Sydney:

Block, D. (2014). Identity in the social sciences today. In Second Language Identities (pp. 13-53). London and New York: Bloomsbury Publishing.

Blommaert, J. (2013). Citizenship, Language, and Superdiversity: Towards Complexity. Language, Identity and Education, 12(3), 193196. doi:10.1080/15348458.2013.797276

Cook, V. (1992). Evidence for multicompetence. Language Learning Journal, 42, 557-591.

Garcia, O., \& Wei, L. (2015). Translanguaging, bilingualism and bilingual education. In W. E. Wright, S. Boun, \& O. García (Eds.), The Handbook of Bilingual and Multilingual Education (First edition ed.): John Wiley \& Sons, Inc.

Gee, J. P. (2008). A sociocultural perspective on opportunity to learn. In P. A. Moss, D. C. Pullin, J. P. Gee, E. H. Haertel, \& L. J. Young (Eds.), Assessment, equity and opportunity to learn (pp. 76-108). New York: Cambridge University Press.

Geertz, C. (1973). The Interpretation of Cultures: Selected Essays. New York: Basic Books.

Gutiérrez, K. D., \& Rogoff, B. (2003). Cultural ways of learning: individual traits or repertoires of practice. Educational Researcher, 32(5), 19-25.

Halliday, M. A. K. (1993). Towards a language-based theory of learning. Linguistics and Education, 5, 93-116.

Kementerian Pendidikan Nasional. (2011). Panduan Pelaksanaan Pendidikan Karakter [Guide to the Implementation of Character Education]. Jakarta: Kementerian Pendidikan Nasional Retrieved from http://repository.unand.ac.id/22742/1/4 PA NDUAN PELAKS PENDIDIKAN KARAKTER.pd $\underline{f}$
Learning to 'do diversity', be versatile and adapt to others is an essential capability for the future. Indonesia has always had a highly syncretic, adaptive ecology of languages and cultures. The post-colonial project of unity in diversity is an on-going one and an intercultural orientation, particularly through language learning, may offer a means for young Indonesians to engage with 'the other' whilst learning more about 'the self', and developing a unique identity in the process. There is an opportunity to engage in this identity question and consider who you/Indonesians can and want to be now and in the future.

Kramsch, C. (2006). From communicative competence to symbolic competence. Modern Language Journal, 90(2), 249-252.

Leung, C., \& Scarino, A. (2016). Reonceptualizing the Nature of Goals and Outcomes in Language/s Education. The Modern Language Journal, 100(Supplement 2016). doi:10.1111/modl.12300 0026-7902/16/8195

Liddicoat, A. J., \& Scarino, A. (2013). Intercultural language teaching and learning. United Kingdom: Wiley-Blackwell.

May, S. (2001). Language and minority rights. London: Longman.

MELC. (2018). Reimagining learning as intercultural engagement. Retrieved from Adelaide:

Mercer, K. (1990). Welcome to the jungle: identity and diversity in postmodern politics. In J. Rutherford (Ed.), Identity: Culture, Community, Difference (pp. 43-71). London: Lawrence and Wishart.

Norton, B. (1995). Social identity, investment, and language learning. TESOL Quarterly, 29(1), 931.

OECD. (2019). Transformative Competencies, The Organisation for Economic Co-operation and Development Learning Compass 2030 Concept Notes. $\quad$ Retrieved from https://www.oecd.org/education/2030project/teaching-and-learning/learning/allconcept-notes/

Prior, M. T. (2019). Elephants in the room: an 'Affective Turn' or Just feeling our way? The Modern Language Journal, 103(2), 516-527.

Risager, K. (2006). Language and Culture: Global Flows and Local Complexity: Multilingual Matters.

Risager, K. (2012). Lingucultural and transnationality: The cultural dimensions of language. In J. Jackson (Ed.), The Routledge Handbook of Language and Intercultural Communication (pp. 101-115). Hoboken: Taylor and Francis.

Scarino, A. (2014). Learning as reciprocal, interpretive meaning-making. A view from collaborative research into the professional learning of teachers of languages. The Modern Language 
Journal (Special Issue), 98(1), 386-401. doi:10.1111/j.1540-4781.2014.12068.x

Scarino, A., \& ACARA. (2014). Australian Curriculum: Languages Foundation to Year 10 Curriculum Design. Sydney: Australian Curriculum, Assessment and Reporting Authority,

Scarino, A., Kohler, M., \& Benedetti, A. (2014). Investigating Pedagogies for language-andculture learning. Retrieved from Adelaide, South Australia: https://www.decd.sa.gov.au/sites/g/files/net 691/f/languages pedagogies report final.pdf? $\mathrm{v}=1466990807$

Shohamy, E. (2007). Language Policy: Hidden Agendas and New Approaches. London and New York: Routledge.

The Douglas Fir Group. (2016). A Transdisciplinary Framework for SLA in a Multilingual World. The Modern Language Journal, 100(Supplement 2016), 19-47. doi:10.1111/modl.12301 